\title{
Agua embotellada en México: de la privatización del \\ suministro a la mercantilización de los recursos hídricos*
}

\section{Introducción}

Raúl Pacheco-Vega*

Las discusiones sobre si es posible operacionalizar el derecho humano al agua conllevan también otros debates sobre la continua mercantili-

zación de los recursos hídricos en forma de agua embotellada,

Actualmente el suministro suficiente de agua potable para consumo humano se encuentra en riesgo severo debido al cambio climático, y existe una crisis de (in)seguridad hídrica. Sorprende el crecimiento exponencial en el consumo del agua embotellada en México, uno de los países con mayor inseguridad hídrica en el mundo. En este artículo presento un análisis del proceso de privatización del suministro del agua en México enfocándome en el negocio de la extracción, el embotellamiento y la distribución de agua embotellada. Utilizando el modelo del régimen de políticas públicas como marco analítico, en el artículo demuestro que el creciente consumo de agua embotellada en México es resultado de la convergencia de ideas específicas con respecto de la salubridad del agua del grifo, un marco institucional débil que cede terreno ante la enorme presión de las empresas multinacionales proveedoras de agua embotellada, y la enorme fuerza tanto mercadotécnica como política con que cuentan las corporaciones embotelladoras del vital líquido.

Palabras clave: agua embotellada, privatización, gobernanza del agua, México, mercantilización.

- Profesor investigador titular de la División de Administración Pública del Centro de Investigación y Docencia Económicas, A. C. (CIDE), campus Región Centro.

raul.pacheco-vega@cide.edu bebidas gaseosas y otros productos envasados. Dado el contexto actual, en el cual está en duda una respuesta positiva a si se tendrá en el futuro el suministro suficiente de agua potable para consumo humano debido a recientes eventos climáticos con drásticos impactos en la disponibilidad de los recursos hídricos, es claro que el tema de la (in)seguridad hídrica tiene importancia preponderante.

Resulta extraño el crecimiento tan drástico que ha habido en el consumo del agua embotellada en México, uno de los países con mayor inseguridad hídrica en el mundo.

\footnotetext{
* Agradezco a mis asistentes de investigación Luis Alberto Hernández y Alejandro Tlacaélel Ramírez por su apoyo en la generación de bases de datos, diagramas y recolección de los datos presentados en este artículo, y Maribel Eudave por el diseño de los diagramas del suministro de agua embotellada. También agradezco los comentarios constructivos de dos dictaminadores anónimos, mismos que enriquecieron el texto. Asumo cualquier error de cálculo y/o interpretación de datos.
} 
En este artículo presento un análisis del proceso de privatización del suministro del agua en México enfocándome específicamente en el negocio de la extracción, el envasado y la distribución de agua embotellada.

En este artículo aplico el régimen de políticas públicas como marco analítico, demostrando que el creciente consumo de agua embotellada en México es resultado de la convergencia de un marco institucional débil, que cede terreno ante la enorme presión de las empresas multinacionales proveedoras de agua embotellada, las ideas específicas con respecto a la salubridad del agua del grifo y el impacto negativo de una brutal fuerza tanto mercadotécnica como política con que cuentan las corporaciones embotelladoras del líquido. Mi análisis confirma que las discusiones académicas sobre privatización del suministro de agua en México han dejado de lado el enorme crecimiento del negocio de agua embotellada. Este crecimiento ha sido resultado de una creciente mercantilización del recurso hídrico. A pesar de una mayor preocupación demostrada en el discurso académico sobre la escasez de agua, recientemente los investigadores en este ámbito han mostrado un interés exacerbado en los fenómenos sociopolíticos de procesos de suministro y distribución del agua desde la perspectiva del acceso equitativo al vital líquido como parte de un proceso de implementación del derecho humano al agua. Sin embargo, un análisis de la situación en el consumo de agua embotellada en México se encuentra ausente de todas estas discusiones sobre el proceso de privatización tan absoluto que ha tenido lugar en México, particularmente con la inclusión de más ciudades como Guadalajara y Puebla entre las posibles zonas metropolitanas mexicanas que piensan establecer mecanismos de privatización y participación privada en la provisión del 
agua. ${ }^{1}$ Por esta razón es importante realizar un análisis de la evolución en el consumo de agua embotellada en el contexto de la privatización del suministro de agua potable, siendo potencialmente posible verlo como resultado de una mercantilización del recurso hídrico.

El artículo está organizado de la siguiente forma: en la primera sección del trabajo (posterior a esta introducción), presento datos sobre el incremento en la extracción, envasado y distribución de agua embotellada en México. También ofrezco un análisis de la evolución en el consumo per cápita por parte de la población mexicana. Estos datos han sido triangulados de numerosas publicaciones, revistas publicadas por la industria, reportes académicos y cifras publicadas en fuentes periodísticas. En la segunda sección presento un panorama de la evolución del consumo de agua embotellada a nivel mundial y comparo el desempeño de la industria mexicana con respecto a su contraparte estadounidense. En la tercera sección presento una revisión de la literatura sobre privatización del agua y el concepto de mercantilización de los recursos hídricos. En la cuarta sección detallo el recorte analítico del régimen de política pública. Este modelo no ha sido aplicado a este tipo de problema anteriormente, y ofrece un gran poder explicativo para comprender la interrelación que existe entre diferentes factores (ideas, intereses e instituciones) para influir en la evolución de una política pública. Si bien en este caso no se analiza una política pública como tal, en la quinta sección aplico el modelo y las variables explicativas para poder analizar y comprender la evolución del negocio del agua embotellada en México y cómo dichas variables se entrela-

I. Sin embargo, hago notar que una discusión relevante en Durán y Torres (2004) también es importante para mi texto, ya que estos autores enfatizan la necesidad de cuantificar los costos ambientales del abastecimiento de agua utilizando el caso de la zona metropolitana, mostrando que es fundamental analizar el suministro desde una perspectiva holística, integrada y de desarrollo sustentable.Agradezco a un dictaminador anónimo el hacerme notar esta reflexión. 
zan para producir el efecto de incremento en el consumo. Finalmente, en las conclusiones se liga la discusión sobre privatización del agua y mercantilización de los recursos hídricos con los resultados del análisis.

\section{El agua embotellada en México: una perspectiva histórica}

Uno de los grandes problemas que tienen los analistas de la industria del agua embotellada es la dificultad de obtener cifras confiables sobre producción, distribución y consumo. Si bien es altamente probable que la afirmación de que "México es el país que consume más Coca-Cola en el mundo" sea cierta, es necesario hacer una revisión exhaustiva y minuciosa de datos para determinar realmente si es una exageración o si es cierto. ${ }^{2}$ Además de ser señalado como el país que más Coca-Cola consume, se le atribuye que es el país en el cual se consume más agua embotellada. ${ }^{3}$ Uno de los problemas más graves en cualquier estudio sobre los procesos sociopolíticos que ocurren alrededor del agua embotellada es la carencia de estadísticas confiables y la homogeneización de los datos. Por un lado, obtener datos sobre extracción, envasado, distribución y consumo de agua embotellada es sumamente difícil a menos que se paguen cantidades exorbitantes para poder leer los reportes de estudios de mercado generados por organizaciones tales como la Beverage Marketing Corporation. ${ }^{4}$ Por otro lado, los datos que están publicados no están homogeneizados en cuanto a sus líneas de base (es decir, algunos reportes

2. Agradezco a un dictaminador anónimo hacer énfasis en que el análisis es dependiente de la fuente de datos. Por ello en el artículo hago bastante hincapié en las diferentes fuentes y su posible confiabilidad.

3. Ver: http://www.maspormas.com/nacion-df/df/el-mayor-consumidor-de-aguaembotellada-en-mexico. Sin embargo, dicho artículo no presenta las fuentes de información, por lo cual es necesario verificar dichos datos.

4. El precio del reporte sobre México oscila sobre los $\$ 5000$ dólares canadienses. Ver: http://www.beveragemarketing.com/reportcatalog la.html 
presentan consumo en litros por año mientras que otros presentan gasto de un hogar por mes, y otros presentan ingreso total de las compañías embotelladoras por venta de agua embotellada).

La intervención de consorcios transnacionales de alta envergadura en el negocio del agua embotellada en México ha sido documentada anteriormente,${ }^{5}$ pero siempre existen variaciones en las interpretaciones del nivel de penetración y grado de captura de mercado. Por ejemplo, algunos autores indican que en Francia la mayor parte del mercado se encuentra concentrado en Vivendi y Suez (Montero Contreras, 2006). Información anecdótica obtenida de medios masivos de información y fuentes hemerográficas indican que tres empresas concentran más del $80 \%$ del mercado de agua embotellada en México. ${ }^{6}$ La empresa francesa Danone y las compañías estadounidenses Coca-Cola y PepsiCo capturan $82 \%$ de las ventas de agua embotellada en México, con un valor de poco más de 10000 millones de dólares. De acuerdo con dicha fuente, Bonafont, de Danone, es el líder en la batalla por el dominio del mercado del agua embotellada en México, al recaudar 38\% de los ingresos que genera esta industria en el país, siguiéndole Ciel de Coca-Cola con 25\%, y e.pura de PepsiCo con un $19 \% .^{7}$

En la Figura 1 presento un diagrama conceptual de cómo pueden diferenciarse los diferentes tipos de agua embotellada de acuerdo con el suministro. El diagrama conceptual permite determinar visualmente las diferentes trayectorias que sigue el vital líquido hasta llegar a los hogares mexicanos.

5. Se recomienda al respecto revisar el trabajo de Montero (2006 y 2008).

6. Los datos presentados son reportados por El Economista, que indica a su vez a Euromonitor como la fuente: $h$ ttp://eleconomista.com.mx/industrias/2012/I0//4/ firmas-extranjeras-duenas-mercado-agua-embotellada.

7. Estas cifras no incluyen a Nestlé, extrañamente. A los cuatro consorcios mencionados se les considera los cuatro jugadores más importantes en el mercado de agua embotellada global. 
Figura 1. Diagrama conceptual del suministro de agua potable para consumo humano y de servicios por hogar e individual

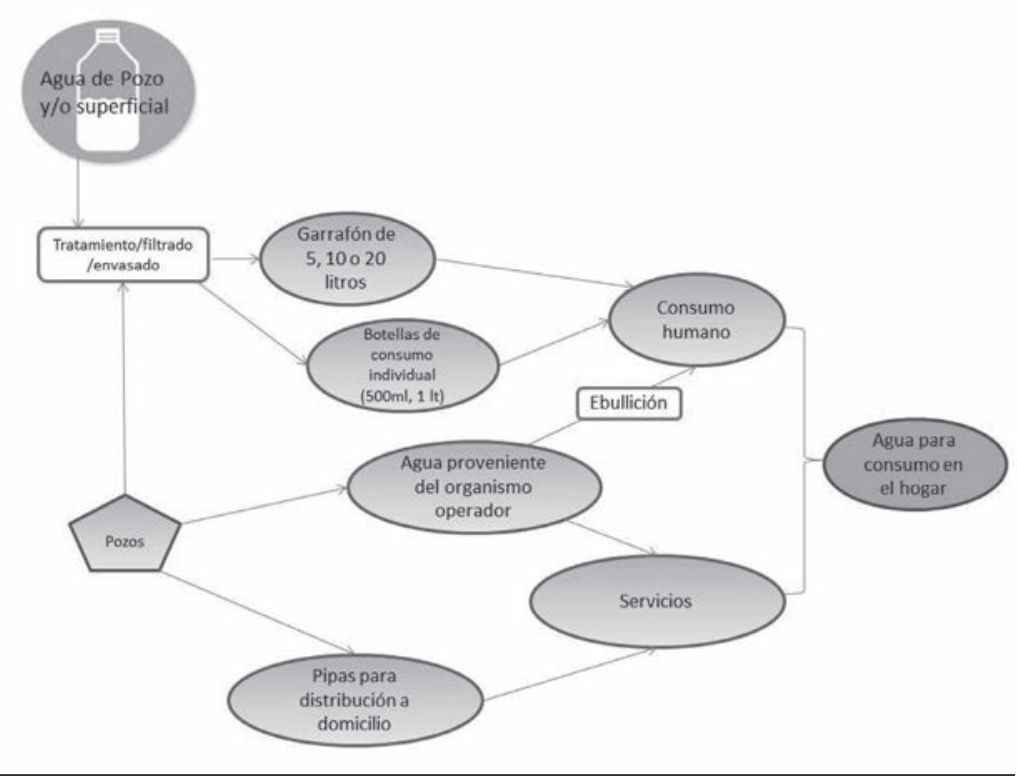

Fuente: construcción propia. El diagrama sitúa el agua embotellada en el contexto.

Como se puede apreciar, los datos presentados por diversas fuentes en fechas similares presentan contradicciones. Por un lado, se indica que el consumo per cápita en México alcanzó los 170.7 litros en el 2011, con lo que se ubica como el tercer consumidor después de los Estados Unidos y China (Morales, 2012). Sin embargo, otras fuentes ubican a México en el segundo lugar mundial en consumo de agua embotellada con un consumo per cápita de 169 litros en el 2009 (Excelencias Gourmet, 2009). En ambos reportes se ubica a Estados Unidos de América como el primer país en términos de consumo per cápita. Sin embargo, reportes más recientes argumentan que México es el primer país a nivel 
mundial en consumo de agua embotellada (Machado, 2013). ${ }^{8}$ Lo interesante es que, a pesar del dominio de las empresas transnacionales, se indica que cerca del $11 \%$ del mercado mexicano se encuentra capturado por más de 7000 micro y pequeñas empresas purificadoras de agua participando en el mercado (El Financiero, 2013). Sin embargo, la certificación de calidad de las pequeñas plantas procesadoras es cuestionable, particularmente porque no existe un sistema de monitoreo y auditoría externa que pueda determinar si los resultados de calidad, tanto bacteriológica como química, son correctos y si las muestras fueron obtenidas de manera confiable. En el caso de las empresas transnacionales, tan sólo en el territorio mexicano, Coca-Cola indica que tiene cincuenta y seis plantas embotelladoras (Coca Cola, 2015). Es posible que la gran mayoría de las mismas se dediquen específicamente a la producción de refresco, por lo que no es posible determinar la fracción de agua envasada en dichas embotelladoras. Es prácticamente imposible por ende determinar exactamente cuánta agua embotellada se produce en una planta específica.

En el presente trabajo ofrezco evidencia empírica no presentada anteriormente en otras fuentes, mediante el cálculo del gasto mensual promedio por cada hogar en agua embotellada y en refrescos. ${ }^{9}$ Utilizando las bases de datos de la Encuesta Nacional de Ingresos del INEGI, calculo el incremento en el consumo de agua embotellada en México utilizando gasto como medida aproximada.

8. Si bien la autora del artículo no menciona el consumo per cápita y por ello es todavía más difícil triangular la cantidad de botellas de agua embotellada realmente consumidas (adquiridas).

9. Agradezco a mi asistente Alejandro Tlacaélel Ramírez por el cálculo de las tablas de datos mencionadas. 
Gráfica 1. Promedio del gasto monetario trimestral de los hogares mexicanos en agua embotellada y refrescos

(2006-2012, unidades en pesos mexicanos corrientes)

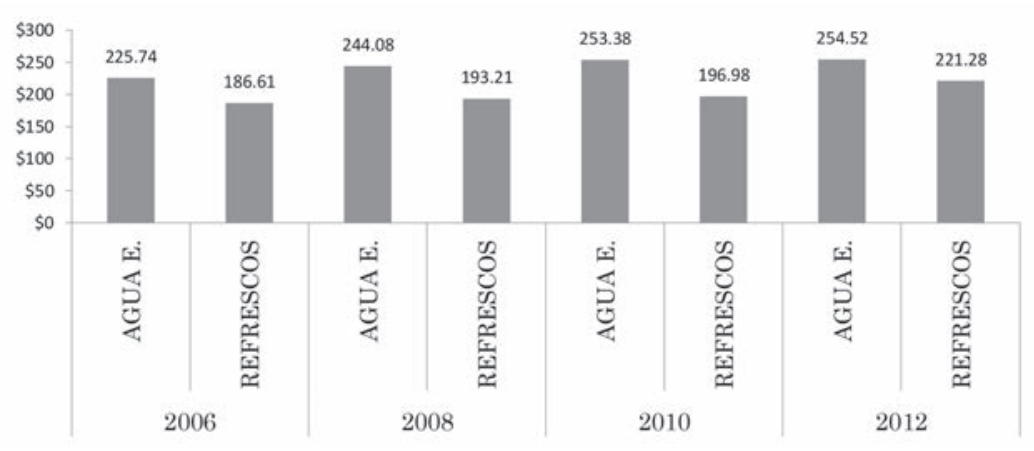

Fuente: elaboración propia con datos de INEGI, Encuesta Nacional de Ingresos y Gastos de los Hogares, varios años.

Como puede observarse en la Gráfica 1, en el periodo 20062012 existió un incremento sostenido, ${ }^{10}$ en ambos casos tanto en el gasto promedio trimestral en agua embotellada como en el gasto en bebidas gaseosas embotelladas (refrescos).

La Gráfica 2 ofrece un panorama muy interesante, ya que demuestra que en promedio los estados en los que los ciudadanos gastan más en agua embotellada son el Distrito Federal, Querétaro, Quintana Roo, Jalisco y Zacatecas. Por poner un ejemplo, Aguascalientes aparece entre los primeros diez, con un gasto promedio trimestral de $\$ 272.23$ pesos. Considerando un costo promedio de garrafón de agua de 20 litros de $\$ 25$ pesos, son aproximadamente once garrafones en el periodo. Esto podría parecer poco para algunos

10. La gráfica presenta los datos ajustando los cambios por índice de precios al consumidor. Se puede demostrar que el incremento no es resultado de un cambio positivo en el precio sino un incremento en el consumo. Se presenta el porcentaje de incremento para ganar mayor poder analítico dado que la base de datos no es de panel. 
analistas, sin embargo, comparativamente, es un gasto importante, con 3.5 garrafones mensuales.

Gráfica 2. Los diez estados con más gasto monetario trimestral en agua embotellada en 2012

(unidades en pesos mexicanos corrientes)

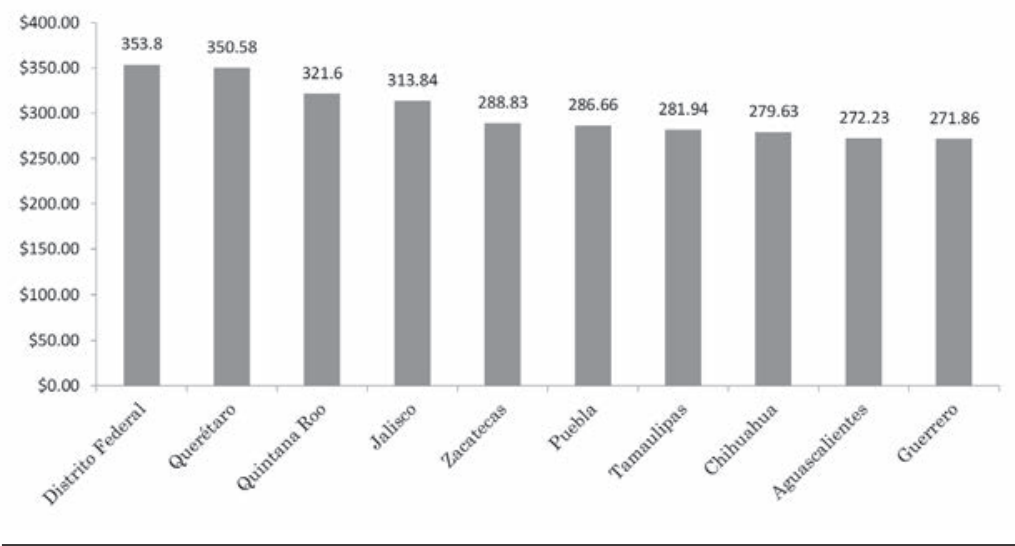

Fuente: elaboración propia con datos de INEGI, Encuesta Nacional de Ingresos y Gastos de los Hogares 2012.

Para contextualizar los datos presentados hasta ahora, en la siguiente sección sitúo el consumo de agua embotellada en México dentro del contexto mundial y en comparación con Estados Unidos de América. Este tipo de comparación es importante por dos razones: en primer lugar, porque permite discernir qué tan cierta es la afirmación que se hace en el sentido de que México es el país en el cual se consume más agua embotellada (difícilmente, ya que somos un país con altísimo estrés hídrico ${ }^{11}$ ) y en segundo lugar, porque nuestro vecino del norte ha tenido tradicionalmente

II. Estrés hídrico se refiere a la presión que sufre un ecosistema por la excesiva demanda de agua comparada con la recarga de los acuíferos. Entonces, el índice de estrés hídrico se calcula como la razón de la extracción a la recarga de agua en un sistema hidrológico determinado. 
costumbres más consumistas, lo cual nos haría pensar que el consumo de agua embotellada en dicho país sería mucho más acentuado que en México.

\section{La evolución del consumo de agua embotellada}

a nivel internacional

Como indiqué en la sección anterior, una de las grandes restricciones para realizar un análisis homogéneo y global del agua embotellada como fenómeno social y político es la falta de datos confiables sobre el consumo de agua envasada y la impenetrabilidad de las compañías embotelladoras y de análisis de mercado para poder obtener información correcta y al día sobre el consumo de agua embotellada. Así mismo, la fusión de los tipos de agua embotellada en una sola categorización hace el análisis todavía más complejo. Más aún, la heterogeneidad de los casos en los cuales hay una controversia por la venta de agua embotellada y la privatización de las fuentes de suministro es muy grande. En algunos países y regiones, es imposible tomar agua directamente del grifo, dadas las pobres condiciones de la infraestructura de suministro. En otros, tenemos un consumo más recreativo y de conveniencia. Y desafortunadamente, quienes calculan las estadísticas sobre consumo de agua embotellada parecen comprimir todas las definiciones, lo cual dificulta todavía más el análisis. En esta sección presento un panorama de la evolución del consumo de agua embotellada a nivel internacional y describo el desempeño de la industria estadounidense. Es importante comparar el consumo de agua embotellada en dos sociedades con niveles socioeconómicos completamente diferentes, ya que la adquisición del producto se comporta a la alza en ambos países independientemente del poder adquisitivo de la población. En el caso de refresco de cola, existe evidencia empírica de que en ciertas regiones de México es mucho más barato (y

\section{0}


accesible) consumir Coca-Cola y sus productos que agua potable (Noguerón Silva, 2013). Lo interesante en este caso es discernir si el agua embotellada como producto se comporta siguiendo un patrón similar.

Gráfica 3. Porcentaje de crecimiento (2010-2011)

en consumo de agua embotellada

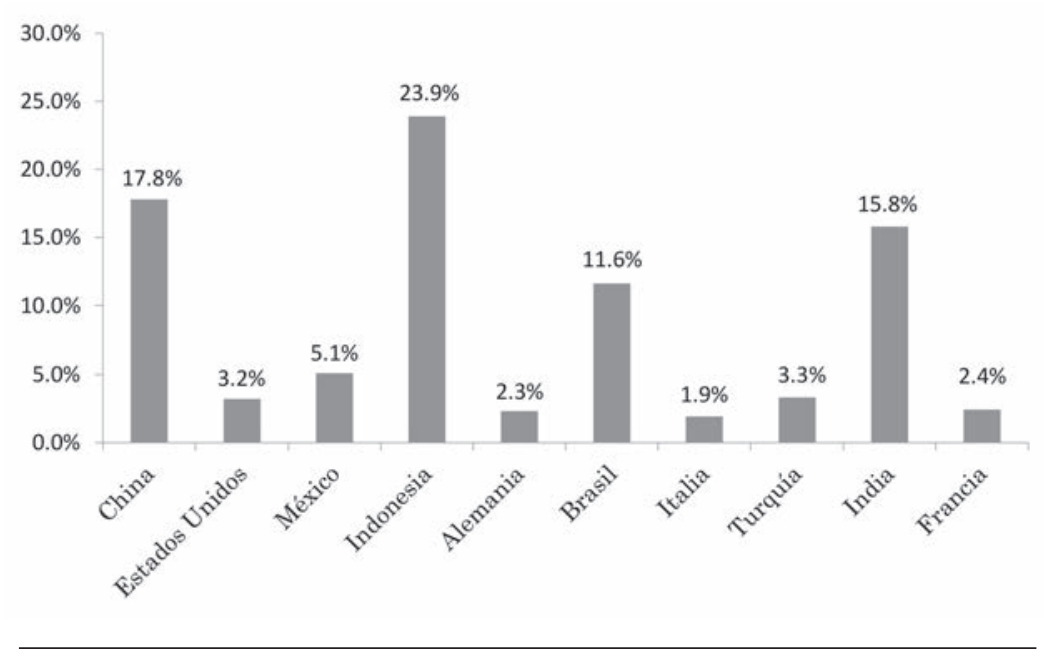

Los países mostrados son los diez con el mayor incremento en consumo de 2010 a 2011.

Fuente: construcción propia con base en cálculos sobre datos de Zenith International Ltd. 2012.

La Gráfica 3 muestra el porcentaje de aumento en consumo de agua embotellada del 2010 al 2011. Si bien en México solamente se aprecia que se eleva en el rango de $5 \%$, es un número substancial, sobre todo si consideramos que México se encuentra dentro de los cinco países con el mayor consumo per cápita de agua embotellada a nivel global. En cuanto a consumo en millones de litros, la Gráfica 4 demuestra una tendencia a la alza, lo cual es preocupante si consideramos el alto grado de presión hídrica global. 
Gráfica 4. Crecimiento en el volumen mundial de agua embotellada en millones de litros (2006-2011)

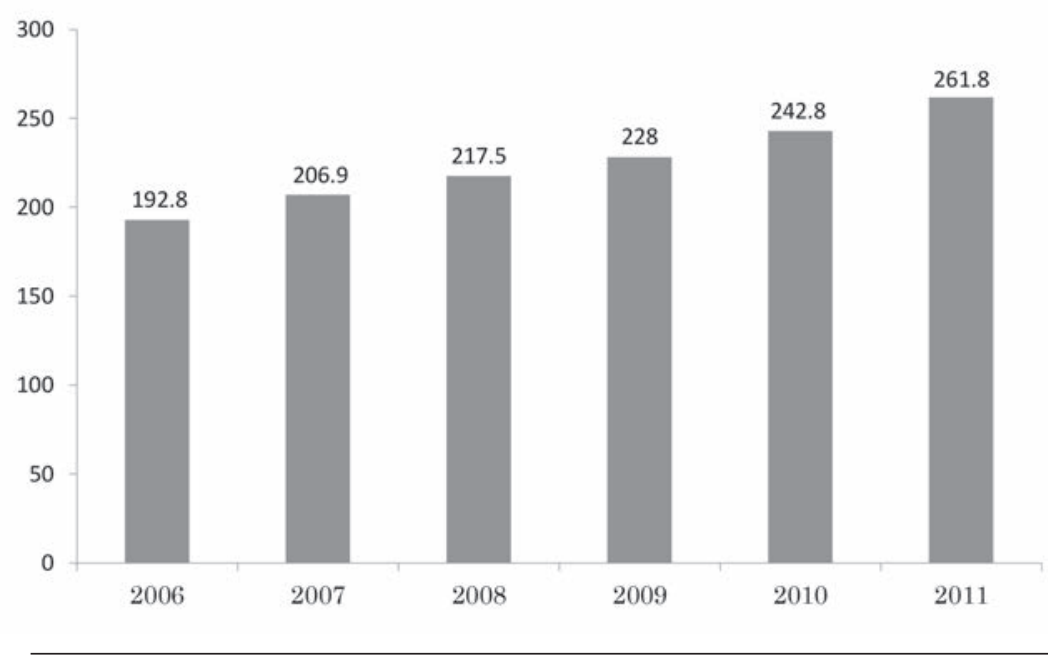

Fuente: construcción propia con base en datos de Zenith International Ltd. 2012.

La extracción, envasado, distribución y consumo de agua embotellada se ha considerado en años recientes como un signo de la prevalencia de una actitud consumista y centrada en la adquisición de bienes (Da Cruz, 2006). Ciertamente este es el caso en sectores tales como el deportivo, donde la hidratación de los jugadores siempre está asociada, tanto en aspectos mercadotécnicos como de procedimiento, con el consumo de bebidas embotelladas (tanto de sabor y energéticas como agua pura filtrada y embotellada-Race, 2012-). A pesar del reciente movimiento en favor del derecho humano al agua y al saneamiento (Schmidt y Mitchell, 2013), y a la reciente reforma constitucional al Artículo $4^{\circ}$ de la Constitución Política de los Estados Unidos Mexicanos (CNN México, 2011), en México seguimos consumiendo agua embotellada. Esta actividad se realiza independientemente del significado simbólico que tiene la adquisición del vital 
líquido envasado para su consumo en raciones individuales: es un simbolismo de la mercantilización del recurso hídrico. Es una demostración y confirmación de que el agua ha dejado de ser un bien público, un recurso al cual tenemos todo el derecho de acceder, y se ha convertido en un bien privado, transable, intercambiable, por el cual se puede pagar un precio. Los grupos sociales y las movilizaciones de organizaciones ambientalistas han puesto gran presión sobre los gobiernos de diversos países (entre ellos México, pero también Bolivia, Argentina y Chile) para ofrecer resistencia a la privatización del agua y promover el derecho al agua y saneamiento como un derecho fundamental (desde la perspectiva de los derechos humanos, en la línea de los DESCA -Derechos Económicos, Sociales, Culturales y Ambientales-).

Como indica Coleman, existe una presión grande sobre los gobiernos nacionales para ofrecer en venta o concesión la asignación de los derechos de usufructo de los mantos acuíferos en América Latina (Coleman, 2012). Esta presión se ve contrapunteada con los débiles sistemas nacionales de establecimiento y asignación de derechos de uso y explotación de pozos. Por lo mismo, resulta crítico y sumamente importante el fortalecer los mecanismos institucionales para la gobernanza del agua embotellada por parte de los gobiernos en los tres niveles: federal, estatal y municipal. Este fortalecimiento es aún más importante cuando consideramos que en México ya se han empezado a impulsar acciones en diferentes escalas (federal, estatal y municipal) para implementar el ya mencionado derecho humano al agua y saneamiento que se consagra en el Artículo $4^{\circ}$ constitucional. El mayor empuje en este rubro proviene generalmente de la sociedad civil, aun cuando hay algunas agencias gubernamentales que están empezando a hacer algunos esfuerzos, particularmente la Comisión Nacional del Agua (CONAGUA). Este tipo de respuestas, incluyendo la 
instalación de abrevaderos públicos son, en gran medida, resultado de movilizaciones de activistas ambientales (Gómez, 2013). ${ }^{12}$

\section{De la privatización del agua a la mercantilización de los recursos hídricos}

Analizar de forma desconectada la dependencia de la sociedad mexicana por el agua embotellada y la incapacidad de los organismos operadores de proveer agua potable de calidad salubre para consumo humano genera una desconexión entre dos grandes áreas de estudio: por un lado, los análisis conceptuales de la privatización del agua, y por el otro, la discusión sobre la adquisición y mercantilización de los recursos hídricos. En el presente trabajo, sigo la tipología conceptual de Leila Harris, quien hace una distinción sobre los conceptos de comodificación, mercantilización y privatización (Harris, 2013). Para Harris los tres vocablos tienen diferentes significados. Privatización (privatization) se refiere a que existe un papel para las compañías privadas en la provisión y gestión del agua, por lo cual típicamente involucra transferencia de algunos o todos los activos de manos públicas a privadas. Comodificación (commodification), en palabras de Harris, es el proceso de convertir un bien o servicio que previamente estaba sujeto a reglas sociales node-mercado a uno que está sujeto a reglas de mercado. La mercantilización (marketization) se refiere a la construcción de mercados para compra y venta, por ejemplo, para derechos de agua (Bakker, 2002). Como indica Harris, es cierto que frecuentemente estas definiciones pueden verse fusionadas y que es difícil determinar exactamente cuál es

12. En el D. F., por ejemplo, más de 5000 capitalinos firmaron una petición para instalar bebederos públicos. En la ciudad de León, el presidente municipal Ricardo Sheffield (de la administración 2009-20I2) instaló una serie de bebederos en el zócalo de la municipalidad. 
el vocablo que mejor aplica para una situación específica. En este artículo asumo que los tres procesos ocurren de manera más o menos traslapada y simultánea.

Como indiqué en el párrafo anterior, uno de los retos principales para establecer un diálogo intelectual entre los diferentes actores interesados en el manejo del agua es que las definiciones en el idioma predominante en la literatura sobre privatización del vital líquido (en inglés) no tienen definición exacta en español. En este caso, tomé la traducción de la palabra commodification ${ }^{13}$ como mercantilización, siguiendo el modelo presentado por la especialista canadiense Karen Bakker. En su trabajo sobre la apertura que España presentó hacia la privatización del servicio, Bakker establece que la introducción de una filosofía de mercado es el paradigma subyacente a la actual mercantilización del recurso hídrico (Bakker, 2002).

La mera idea de la comodificación (o mercantilización) del recurso hídrico resultaba totalmente inusitada e impensable en los años sesenta en los Estados Unidos de América. Como bien precisa Jim Salzman en su detallada historia del agua potable en la arena mundial, y enfocándose específicamente en el caso de los Estados Unidos, en los años sesenta este concepto de envasar agua (que generalmente era proveniente del suministro municipal y solamente era filtrada previo al envasado) era casi una herejía (Salzman, 2012).

A pesar de los debates ideológicos alrededor de la privatización del agua, en sí misma no tiene ningún tipo de beneficio o perjuicio inherente. Como bien indica Bakker, hay instancias en las cuales la privatización de la producción de los servicios públicos de agua potable y alcantarillado ha tenido consecuencias positivas (Bakker, 2010). Obviamente, también hay instancias y ejemplos en los cuales

13. Algunos autores sugieren que la palabra "comodificación" es correcta, pero me parece que en este caso resulta un anglicismo. Como indico en el texto, la palabra mercantilización me parece más adecuada. 
ha tenido efectos sumamente negativos (Azpiazu, 2004). Es necesario evaluar los casos de privatización de manera individual ya que es difícil realizar generalizaciones sobre los beneficios de la transferencia de las responsabilidades de provisión de un servicio público tan importante como el agua a entidades privadas. Hay evidencia empírica tanto en favor de la privatización del suministro público de agua potable y alcantarillado (Galiani, Gertler y Schargrodsky, 2005) como en contra (Davis, 2005; Hardoy y Schusterman, 2000; Pirez, 2002; Shiva, 2002). El debate alrededor de la privatización no es tangencial al estudio de las fuerzas políticas que enmarcan el consumo de agua embotellada. Por el contrario, la privatización del suministro de agua tiene una relación causal directa sobre el crecimiento en el consumo de agua embotellada tanto en la escala individual como en los hogares mexicanos. En gran parte, este proceso es el resultado de las percepciones individuales de la salubridad del líquido distribuido en el sistema de aguas.

Uno de los aspectos más importantes en la discusión tanto de la privatización del agua como de la mercantilización del recurso hídrico es una discusión macro sobre el papel de los municipios (o de las ciudades, dependiendo del modelo organizacional y la estructura de política pública en materia de provisión de agua) en el suministro del vital líquido. La discusión en escala macro a la cual me refiero es la filosofía inherente a la privatización del agua por parte de quienes la promueven: el paulatino alejamiento del gobierno de las funciones primordiales de provisión de servicios. Quienes argumentan por una organización menos jerárquica y por un gobierno menos "pesado" (es decir, que incurra en menor gasto público) han promovido el concepto de gobernanza como el retiro del Estado (Pacheco-Vega y Vega, 2008). Es decir, en aras de buscar reducir gastos del erario público en la provisión del agua potable a través de un modelo de alejamiento del Estado, las empresas privadas entran a 
"ayudarle" a los gobiernos municipales a resolver un problema de suministro de un servicio público. Como demuestra Furlong en su estudio de gobernanza de agua en la provincia de Ontario (Canadá), el surgimiento de propuestas de Alternative Service Delivery (Entrega de Servicio Alternativa) es el resultado de las dificultades que encaran los municipios para proveer de agua salubre, potable y de buen sabor a sus ciudadanos (Furlong, 2012). Alternative Service Delivery (ASD) involucra la transformación del servicio del suministro con el subsecuente cambio en la estructura organizacional y en la estructura regulatoria. En la estructura organizacional, las relaciones e interacciones entre el proveedor privado del agua y el organismo operador se amalgaman para lograr un efecto de alta coordinación. El problema, en el caso mexicano, es que dicha amalgamación tiene un efecto negativo en la coordinación interjurisdiccional y en la relación entre las empresas pública y privada.

La decisión de la provisión de agua en el ámbito público mexicano tiene múltiples aristas, y su análisis presenta complejidades que no son claramente visibles a primera vista. En primer lugar, hay que retomar el Artículo $4^{\circ}$, sexto párrafo, de la Constitución Política de los Estados Unidos Mexicanos, ${ }^{14}$ donde se establece el derecho de los ciudadanos al acceso del agua potable de forma suficiente y de calidad, además de que el Estado garantizará este derecho. La obligación de ofrecer el servicio de agua potable y alcantarillado a los usuarios (en este caso, a los ciudadanos) recae en los municipios, como resultado de la atribución establecida en el Artículo 115, inciso III, de la ya mencionada Constitución Política. ${ }^{15}$ Sin embargo, ni en el inciso y artículo mencionados, ni en ninguna otra sección de la Ley de Aguas Naciona-

14. Puede ser consultado en extenso en el enlace: http://www.ordenjuridico.gob. $\mathrm{mx} /$ Constitucion/articulos/4.pdf

15. Puede ser consultado en extenso en el enlace: http://www.ordenjuridico.gob. $\mathrm{mx} /$ Constitucion/articulos/I I5.pdf 
les existe algún tipo de restricción visible y escrita en detalle con respecto del tipo de suministro de agua para consumo humano (para beber). A pesar de que la obligación de los municipios es proveer de este servicio a través de los organismos operadores de agua, como establece la Ley de Aguas Nacionales, la percepción del público mexicano de que los municipios en los cuales viven son incapaces de la provisión de agua potable para consumo humano directamente del grifo, combinada con el estado deficiente de la infraestructura municipal en muchas de las ciudades mexicanas, ha contribuido a que los mexicanos hayan iniciado un proceso de sustitución de la fuente originalmente designada para garantizar el aseguramiento de su provisión individual y en el hogar del vital líquido (el grifo) por la adquisición de garrafones de 20 litros que son vendidos y distribuidos a todos los domicilios por representantes tanto de empresas transnacionales (como Coca-Cola, a través de FEMSA) o en menor grado, por empresarios locales que consiguen una concesión para la producción de agua embotellada.

En segundo lugar, aun en casos de municipios mexicanos en los cuales la provisión del servicio de agua es privatizada, ${ }^{16}$ el consumo de agua embotellada continúa existiendo. A esto contribuye en parte el marco regulatorio y de legislación ambiental y del agua en México, que es tan complejo que no existen artículos específicos, reglamentos u ordenanzas en las cuales se regule la actividad de extracción, envasado, distribución y venta al menudeo de agua en dosis individuales (o incluso en formato para consumo en el hogar de garrafones de 20 litros). El caso de la desregulación (o pobre regulación, en su caso) de la industria del agua embotellada en México no es el único. En Canadá es una actividad mayormente desregulada (Trottier, Ferguson, Cook, Maggio y Cressy, 2009), sobre todo con la gran ventaja 
de que el suministro de agua potable para consumo humano proviene primordialmente de lagos y presas, mientras que en México, la extracción del vital líquido es una actividad que pone aún mayor estrés hídrico en los acuíferos que ya de por sí están bastante agotados. Estados Unidos de América tampoco se queda muy atrás con la desregulación de la industria del agua embotellada.

Entre los casos detallados como referencia contextual en este trabajo, muchos se relacionan con ciudades o provincias canadienses. Resulta difícil no incluir a Canadá y a los activistas canadienses en un análisis de la discusión alrededor del agua embotellada. Una de las principales promotoras del movimiento del agua del grifo y antiprivatización ha sido la activista canadiense Maude Barlow, autora de, entre otros, el libro Bottled and Sold, y quien durante 2008-2009 fue la Consejera Especial sobre Agua del Secretario General de las Naciones Unidas. ${ }^{17}$ En realidad es un poco paradójico el que una activista canadiense haya iniciado un movimiento para proteger los recursos hídricos de la privatización en un país que está dotado con una gran proporción del agua mundial. No obstante, los activistas canadienses han logrado fortalecer el movimiento antiprivatización de manera sustancial.

Al mismo tiempo que ha habido batallas encabezadas por múltiples activistas para hacer que los municipios prohíban la venta de agua embotellada en su territorio, también ha habido algunos esfuerzos por parte de gobiernos municipales de restringir la venta y consumo de botellas de agua en las oficinas gubernamentales. Si bien de alcance muchísimo más limitado, este tipo de iniciativas resulta importante porque demuestra una cierta conciencia ambiental por parte del gobierno municipal. En años recientes se ha observado en América del Norte una tendencia creciente a

17. La biografía de la activista Maude Barlow puede ser consultada en el siguiente enlace: http://www.canadians.org/maude 
tener gobiernos municipales en las grandes ciudades que han realizado esfuerzos para poder reducir el consumo de agua embotellada en sus centros de trabajo, es decir, en las oficinas gubernamentales. Por ejemplo, en la ciudad canadiense de Toronto, en diciembre del 2008, el gobierno municipal decidió prohibir la venta y distribución de agua embotellada en las oficinas de la ciudad (Clarke, 2008). Varias ciudades en Canadá han promovido iniciativas similares. Por ejemplo, el poblado de Charlottestown en Prince Edward Island promovió una iniciativa en el 2007 para prohibir la adquisición de agua embotellada en los edificios de las oficinas gubernamentales (Smith, 2007).

Los esfuerzos para restringir o prohibir la venta de botellas de agua en instalaciones gubernamentales no han estado solamente enfocados a los gobiernos municipales. La provincia canadiense de Manitoba prohibió en el 2011 el consumo de agua embotellada en todas sus oficinas gubernamentales, con el fin de promover la ingestión de agua del grifo (The Independent, 2011). Manitoba no ha sido la única provincia canadiense que ha prohibido el consumo de botellas de agua en las instalaciones de sus oficinas gubernamentales. También Nova Scotia lo hizo en el 2010. Ambas provincias fueron objeto de múltiples alabanzas por sus esfuerzos para reducir la acumulación de plástico en los basureros municipales y por promover el consumo de agua del grifo (CBC News, 2010). En los Estados Unidos de América también ha habido varios casos de gobiernos municipales que declaran una moratoria sobre la adquisición de botellas de agua para consumo humano en sus instalaciones. Por ejemplo, en junio del 2007, se originó una competencia entre San Francisco y Santa Bárbara, ciudades californianas en las cuales ya había antecedentes de intenciones por parte de sus presidentes municipales de dejar de adquirir agua embotellada para uso de los empleados del gobierno de la ciudad (Welsh, 2007). Si bien Santa Bárbara se adelantó 
por un par de meses a San Francisco, ambas ciudades norteamericanas demostraron que es posible detener (aunque sea de forma relativamente simbólica) la mercantilización del recurso hídrico mediante las moratorias a la adquisición de garrafones y botellas de agua.

Una acción gubernamental diferente y de alcance e impacto muchísimo más fuerte y visible es la prohibición de la venta del vital líquido en su forma envasada en el territorio de una cierta jurisdicción. En Estados Unidos, por ejemplo, el poblado de Concord, Massachusetts, publicó recientemente un reglamento en la cual indica que la venta de agua embotellada no mineral ni gaseosa es ilegal (Locker, 2013). De acuerdo con este reglamento publicado por Concord, es ilegal vender agua sin sabor, no gaseosa, en botellas para consumo individual de un litro (34 onzas) o menos en el pueblo de Concord a partir del primero de enero del 2013. Es notable la claridad y especificidad en la redacción del reglamento, ya que uno de los problemas más graves cuando se analizan datos sobre el consumo de agua embotellada en México o en el mundo es que se agrupan las cifras sobre envase, producción y distribución de agua embotellada incluyendo bebidas gaseosas, no gaseosas, con sabor, agua mineral y agua puramente filtrada, botellas para consumo individual y garrafones para consumo en el hogar. El texto de la enmienda, en su idioma original, dice:

It shall be unlawful to sell non-sparkling, unflavored drinking water in single-serving polyethylene terephthalate (PET) bottles of I liter (34 ounces) or less in the Town of Concord on or after January I, 2013. ${ }^{18}$

Estos esfuerzos de combatir la privatización y el negocio del agua embotellada en la escala gubernamental municipal y

18. El texto completo del reglamento se encuentra aquí: http://www.concordma. gov/pages/ConcordMA_TownClerk/Water\%20Bottle\%20Bylaw.pdf 
estatal se complementan con las campañas universitarias en favor del consumo de agua del grifo. Por ejemplo, la sociedad de alumnos (Alma Mater Society) de The University of British Columbia (también en Vancouver) organizó una vigorosa campaña que unió tanto al alumnado como al profesorado y al staff de la universidad en un movimiento en contra del agua embotellada en el campus, denominada "Tap That"19 (un juego de palabras que significa, aproximadamente, "toma eso", pero que tiene su inspiración en el agua del grifo, en inglés tap water). Este proyecto tenía como objetivo cambiar los patrones de consumo de agua embotellada de los estudiantes, profesorado y staff de la universidad, incrementando el número de bebederos y grifos para llenado de botellas portátiles (Pritchard, Douglas y Zhang, 2010). Un gran número de grupos con intereses similares en otras universidades en Canadá han replicado el proyecto. La iniciativa Public Water Initiative, de la University of Toronto, ha compilado un resumen de las universidades canadienses en las cuales se ha prohibido la venta de agua embotellada, incluyendo University of Winnipeg, University of Ottawa, Ryerson University, Memorial University St. John's y Brandon University. La Federación Canadiense de Estudiantes promueve una campaña sobre el derecho humano al agua llamada "Back The Tap!."”

No solamente ha habido algunos municipios o provincias o estados que se han pronunciado por eliminar completamente la venta de agua embotellada. En parques nacionales también se libra la batalla contra el suministro privado de agua. Por ejemplo, en el parque del Grand Canyon en los Estados Unidos, a partir de enero del 2012, la venta de agua embotellada para consumo individual (single-serving) se ha

19. El sitio web del programa se encuentra aquí: http://tapthatubc.com/about/.Se puede encontrar más información sobre la campaña en el presente sitio: http:// ubyssey.ca/news/celebrating-the-tap-765/

20. Traducida al español como “ifortalece el grifo!”. 
restringido hasta el punto de la prohibición. Si bien hubo una oposición substancial por parte de Coca-Cola Company (Barringer, 2011) para que dicha proscripción no tuviera lugar, en enero del 2012 entró en vigor la prohibición.

Una de las restricciones más importantes que sufren los consumidores es el acceso al agua no solamente desde la perspectiva de la portabilidad, sino también de la provisión del vital líquido mediante bebederos para consumo individual, tanto humano como animal. Los bebederos eran artefactos comunes en las sociedades de países desarrollados, aunque también estaban presentes en comunidades y regiones de países en vías de desarrollo. En Vancouver (la zona metropolitana más grande de la provincia canadiense de British Columbia) y en Victoria (la capital de la misma provincia, localizada en la isla vecina de Vancouver Island), en años recientes ha habido un gran impulso a programas de prevención del consumo de agua embotellada y de provisión de agua en bebederos en centros urbanos (Gelb, 2007). En el caso mexicano, no existe una base de datos que permita determinar cuántos abrevaderos para consumo humano se tienen en las ciudades. De manera anecdótica, algunas ciudades como Puebla y León y algunas escuelas han creado campañas para instalar este tipo de fuentes de agua potable en centros históricos (Flores, 2013).

\section{El modelo del régimen de política pública}

Para poder entender este fenómeno de evolución de la privatización del agua hacia la mercantilización del recurso hídrico en México, utilizo el modelo del régimen de política pública. Este no ha sido aplicado a este tipo de problema anteriormente, y sin embargo ofrece un gran poder explicativo para comprender la interrelación que existe entre diferentes factores (ideas, intereses e instituciones) para influir en la evolución de una política pública. Si bien la 
aplicación más general de este marco analítico es al estudio de la evolución de una política pública y al cambio de política conforme transcurre el tiempo y evolucionan las condiciones de operación, en este caso aplico los elementos del mismo para comprender la interrelación de las variables que potencialmente pueden explicar el fenómeno del aumento en el consumo de agua embotellada, en México y en el mundo.

Figura 2. El marco del régimen de política pública

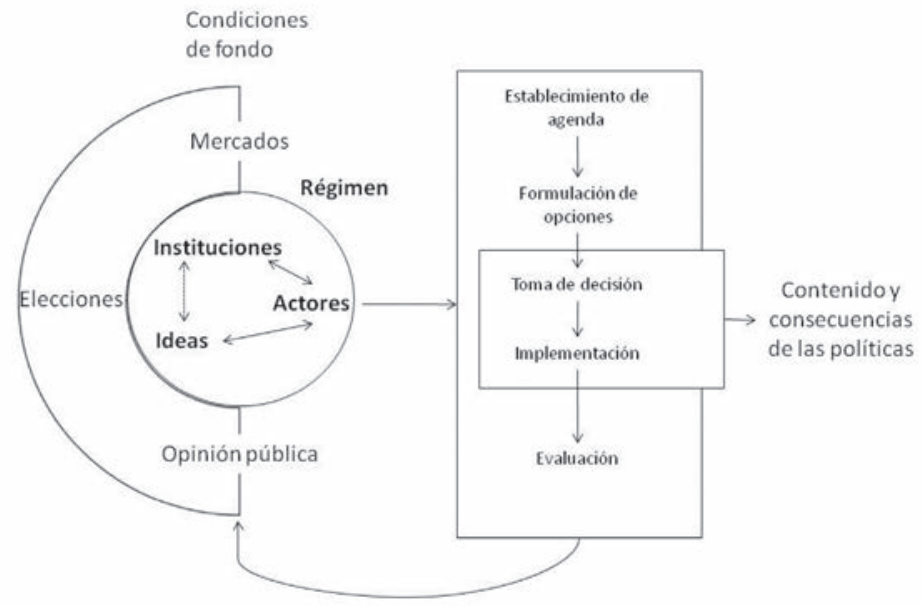

Fuente: adaptado de Hoberg (2002).

Este análisis establece que la evolución y el cambio en políticas es el resultado de la interacción de tres variables explicativas primordiales: los intereses (actores), las instituciones, y las ideas (Flaherty, Pacheco-Vega e Isaac-Renton, 2011; Howlett, 2009). Dichas variables y sus efectos no existen en un vacío, sino que son el resultado de repetidas interacciones en múltiples escalas. Las tres variables que ofrecen un contexto de acción para la interacción entre ideas, 
intereses e instituciones, incluyen el estado de los mercados, la opinión pública y los procesos electorales (Hoberg, 2002).

En el modelo propuesto por Hoberg, el primer proceso tiene lugar mediante el establecimiento de la agenda de política, seguido por la formulación de opciones y selección de instrumentos. Posteriormente, el proceso de toma de decisiones y de implementación conforman lo que se denomina como el contenido y consecuencia de la política pública (qué se va a hacer y cómo se va a implementar, y cuáles son los resultados esperados). Finalmente, en la etapa de evaluación, el analista de políticas públicas determina cómo el proceso se lleva a cabo y si los indicadores seleccionados para evaluar los resultados esperados en términos de cambio de política son los satisfactorios. Como se observa en el diagrama, todo el proceso de construcción e implementación de políticas públicas no ocurre en un vacío, sino que puede también tener algún efecto retroalimentador sobre las condiciones de fondo: los mercados, las elecciones y la opinión pública.

Las condiciones de fondo que describe Hoberg forman el contexto en el cual opera el régimen de política. Las instituciones, ideas e intereses o actores interactúan, se entrelazan y de forma conjunta ofrecen una explicación al fenómeno de cambio de política. En este modelo, la forma en la que se transforma o evoluciona una política (ya sea en su etapa de construcción de agenda o de implementación) se ve influida por la interacción entre intereses, instituciones e ideas. Los intereses (es decir, los actores con algún interés en el asunto) pueden actuar de forma conexa con las ideas tanto de los actores que participan en el proceso de construcción e implementación de la política como con las instituciones en cuyo marco opera la política analizada.

Estos tres elementos tienen diferentes grados de poder explicativo, y en una diversidad de casos pueden tener mayor o menor relevancia. En algunos casos, como el 
presentado por Pacheco-Vega en su análisis de la política de tratamiento del agua residual en los cinco estados de la cuenca Lerma-Chapala, la variable que ofrece mayor poder explicativo es el marco institucional debilitado de los consejos de cuenca (Pacheco-Vega, 2012). En el estudio presentado por Harrison que compara la variación en las respuestas por parte de los Estados Unidos, Canadá y Suecia en materia de regulación de dioxinas de la industria de la pulpa y el papel, las ideas ofrecen el mayor poder explicativo (Harrison, 2002).

Si bien este marco analítico se ha aplicado prácticamente en la mayoría de los casos al estudio de la evolución o cambio de política pública, en el caso de la resolución de conflictos sobre el dilema alrededor de las estrategias de protección del oso del gran bosque húmedo (Great RainForest Bear por su nombre en inglés) presentado por Saarikoski, Raitio y Barry, ellos aplican este análisis combinado con la teoría de negociación colaborativa (Saarikoski, Raitio y Barry, 2013). Usando una estrategia analítica similar, en este artículo aplico el recorte analítico del régimen de política a un caso de estudio sobre agua embotellada, sin enfocarme en alguna etapa específica del ciclo de las políticas públicas, sino únicamente evaluando el impacto de las ideas, intereses e instituciones sobre el incremento en el envasado, distribución y consumo del agua embotellada en México. En la siguiente sección presento el resultado de la aplicación del modelo.

Aplicando el recorte analítico al caso de estudio: ideas, intereses e instituciones en el contexto del negocio de agua embotellada en México

Si bien en este caso no se analiza una política pública como tal, es posible utilizar el modelo y las variables explicativas para poder analizar y comprender la evolución del 
negocio de agua embotellada en México y cómo dichas variables se entrelazan para producir el efecto de la expansión en el consumo. El análisis está dividido en tres apartados principales: la influencia de las ideas tanto en relación con la percepción del agua embotellada como del agua corriente, el marco institucional debilitado y desarticulado en materia de regulación de agua embotellada en México, y los intereses de actores cuyo principal negocio es la provisión del vital líquido en convenientes dosis de 500 mililitros, 1 litro y 20 litros.

En primer lugar, el papel de las ideas como variable explicativa ofrece una interesante aproximación al problema. Hay un gran número de ideas en discusión, conversación y contraposición en el caso del agua embotellada en México. Una de las ideas prevalentes en la población es que el agua potable distribuida a los domicilios por los sistemas operadores de agua potable y alcantarillado no es de la calidad bacteriológica y de pureza química requerida. La creciente preocupación de la sociedad mexicana con respecto a la calidad del agua del grifo ha redundado también en un incremento en el consumo de agua en botella. Si bien al menos un estudio de características de calidad de una muestra de botellas de agua (Castro-del-Campo y Chaidez-Quiroz, 2011) manifiesta que esta parece cumplir con los requisitos de calidad, no se ha realizado un estudio exhaustivo comparativo entre la calidad de agua embotellada y del grifo. De cualquier forma, la población mexicana continúa consumiendo el líquido en su forma portátil. Lo interesante es que la portabilidad de la botella parece ser uno de los factores más relevantes en el cambio de actitudes con respecto del consumo (Race, 2012).

Otra idea que tiene influencia en cómo ha penetrado el negocio de agua embotellada en México es la tendencia en años recientes por parte de los restaurantes y hoteles de ofrecer agua embotellada. Irónicamente, en los Estados 
Unidos, desde el 2007, restaurantes famosos en Boston, New York y San Francisco eliminaron el agua embotellada de sus menús (Carpenter, 2007). Como se menciona en un artículo de Carpenter (2007), algunos restaurantes gozan de un sobreprecio bastante atractivo, desde $\$ 1.00$ dólar americano hasta $\$ 6.00$ dólares.

En Italia, por ejemplo, Black ha demostrado que el agua mineral (específicamente el agua embotellada mineral) ha logrado tomar un lugar en la mesa, a pesar de que realmente la calidad del agua del grifo es relativamente buena (Black, 2009). En el estudio histórico y etnográfico sobre el agua mineral de Sangemini en Umbria, Italia, que es el caso presentado por Black, se tiene una peculiaridad, ya que los patrones de consumo en los regímenes alimenticios italianos incluyen agua mineral, no agua corriente. Como indica Black,

en Italia es casi impensable colocar una jarra de agua del grifo en la mesa, mucho menos contaminar un vaso con agua con hielo de origen cuestionable. Si bien el agua mineral embotellada solamente se ha convertido en una bebida común en el último siglo, tiene un lugar central en la mesa, el cual frecuentemente está localizado junto al vino (Black, 2009, p. 196).

Ciertamente, existen buenas razones para sospechar de la ineficacia de los gobiernos municipales de proveer de agua de buena calidad a los ciudadanos. En primer lugar, la infraestructura puede estar deteriorada. En segundo lugar, dada la extrema dependencia de los sistemas de agua potable y alcantarillado de la extracción de agua de pozos, y considerando que la calidad del vital líquido en los mantos acuíferos puede haberse visto deteriorada, no resulta descabellado pensar que el agua que llega a los grifos de las

\section{8}


casas no es apta para el consumo humano. ${ }^{21}$ Por ello resulta compleja la relación entre los ciudadanos y sus sistemas operadores de agua potable y alcantarillado. La responsabilidad recae en los organismos operadores como las agencias gubernamentales encargadas de la provisión del servicio (Domínguez Alonso, 2011). Sin embargo, dichos organismos operadores no siempre tienen la capacidad de ofrecer agua potable en las condiciones adecuadas bacteriológicas y físicoquímicas para poder ser consumida directamente del grifo. La pregunta que uno debe plantearse es entonces ¿cómo podemos fortalecer a los organismos operadores de agua?

De igual manera, la influencia de los intereses financieros de las grandes corporaciones es un factor preponderante en la forma en la que el consumo de agua embotellada ha aumentado. La intervención de empresas transnacionales en la provisión de agua al público ha crecido de forma exponencial en años recientes. Estas corporaciones tienen la capacidad económica de ejercer presión sobre gobiernos locales tanto para invertir y participar en el negocio de venta de agua embotellada como en el suministro de agua como servicio público. Como indica Delia Montero, la participación de los grandes conglomerados que adquieren concesiones para la extracción y purificación de agua para su embotellamiento ha dado lugar a un negocio de enormes proporciones (Montero Contreras, 2008). La incursión masiva de los consorcios transnacionales de agua embotellada en México valida la inclusión de la segunda variable del marco del régimen de política pública: los intereses. Como se ha hecho patente en años recientes, el cabildeo por parte de las empresas embotelladoras en contra del agua de grifo ha sido sumamente agresivo. Estas actividades de lobbying no

21 . Además hay que tener en cuenta que en México no está extendida la cultura de limpiar regularmente y con periodicidad los contenedores de agua doméstica tales como aljibes y tinacos. Agradezco la observación de un dictaminador anónimo a este respecto. 
han tenido lugar solamente en México, sino también en los Estados Unidos y otros países. Por ejemplo, en relación con las bebidas gaseosas, el ex alcalde de New York, Michael Bloomberg, creó una agresiva iniciativa contra la obesidad y las bebidas gaseosas ${ }^{22}$ que le ha ganado enemistades y críticas (como por ejemplo, un artículo relativamente reciente que indicaba que la tasa de obesidad en Nueva York creció $25 \%$ durante el mandato de Bloomberg). ${ }^{23}$ Este mismo tipo de cabildeo agresivo y altamente negativo ha resultado en la penetración cada vez más profunda de los conglomerados transnacionales de envasado del agua.

El impacto de la estrategia mercadotécnica de los grandes consorcios de agua embotellada en México sobre el comportamiento del consumidor de agua no puede soslayarse. Mientras que hace unas décadas el concepto de agua embotellada era prácticamente risible, en épocas recientes se ha convertido en un negocio redondo, particularmente en países como México donde la susceptibilidad de la población a la mercadotecnia es considerablemente alta. Es interesante hacer notar que el concepto de agua embotellada ni siquiera entraría en la mente de los residentes de Fiji (Kaplan, 1994; Ulrich, 2009). A pesar de ello, la marca de agua embotellada Fiji Water es reconocida visualmente en la esfera internacional como una de las más populares. Las actividades promocionales de Coca-Cola llegan a alcanzar un nivel estratosférico, al grado que el fenómeno de aculturación en el cual se conoce la marca "Coke" o "Coca-Cola" se denomina la "coca-colonización". Es de hacer notar que el sitio web de Coca-Cola en México no promueve un manejo

22. Para más detalles ver: http://www.mikebloomberg.com/index. cfm?objectid=B7EE3B90-C29C-7CA2-FE35C0860A2075BD

23. Para más detalles ver:http://www.huffingtonpost.com/2013/09/30/nyc-obesityrate_n_4016063.html

\section{0}


sustentable del agua, sino que se enfoca en demostrar que sus bebidas no contribuyen a incrementar la obesidad. ${ }^{24}$

Los intereses enfocados en la mercantilización del recurso hídrico no son solamente transnacionales. Si bien Nestlé, Coca-Cola, Danone y PepsiCo son los cuatro gigantes productores de bebidas embotelladas que concentran mayormente el mercado de agua embotellada en México, el negocio de envasado de agua filtrada y purificada ha ido creciendo, en gran parte mediante el establecimiento de franquicias que son promovidas agresivamente en medios masivos de comunicación y redes sociales. ${ }^{25}$

Finalmente, el marco regulatorio y de instituciones en México en materia de agua, y específicamente en relación con la privatización es sumamente débil. No solamente no se tiene una base de datos o un cuerpo de conocimiento sistematizado con respecto a las experiencias mexicanas en materia de privatización, sino que los gobiernos municipales parecen tener un ávido interés en ofrecer y otorgar concesiones y entrar en alianzas público-privadas con empresas del sector del agua para ofrecer el servicio de agua potable y alcantarillado. Incluso a pesar de las fallas claramente documentadas en los procesos de privatización como en el caso de Aguascalientes (Caldera Ortega, 2006; PachecoVega, 2013), el énfasis e interés en la participación privada de servicios públicos hidráulicos es paradójico. Una posible hipótesis con respecto a la debilidad del marco institucional es que los gobiernos municipales se autoperciben como incapaces de ofrecer agua de calidad para el consumo humano con la infraestructura existente y, por ende, permiten e incluso fomentan la participación privada.

24. Un ejemplo claro se encuentra en: http://www.coca-colamexico.com.mx/ beneficios_bebidas.html

25. Más detalles ver: http://franquiciasyfranquicias.com/blog/negocio-seguro-confranquicias-de-agua-purificada/ 
El aparato regulatorio en materia de privatización en México sigue siendo vago, y el aprendizaje por parte de las autoridades locales, estatales y municipales ha sido mínimo. No existen mecanismos de coordinación entre los diferentes niveles de gobierno ni tampoco hay una estrategia coordinada para atacar y resolver los problemas que genera la falta de infraestructura para la provisión de agua potable por parte de los organismos operadores. Visto desde una perspectiva neoinstitucionalista, no existen las instituciones que servirían para otorgar seguridad y dar estabilidad a los contratos establecidos entre las municipalidades y las empresas que extraen agua para su envase, distribución y venta. Incluso en municipios con altísimo nivel de estrés hídrico, como son los casos de León, Aguascalientes y Puebla, hay concesiones para embotellar tanto agua para consumo individual como refresco (La Jornada de Oriente, 2013) a pesar de que el costo del agua puede ser hasta más de 10000 veces lo pagado por la concesión del agua (Enciso, 2009).

La desarticulación entre los diferentes niveles de gobierno (municipal, estatal y federal) y la falta de coordinación entre las diversas agencias gubernamentales que tienen alguna injerencia en el control de las concesiones para la explotación de mantos acuíferos en México y para la extracción, distribución, envase y venta de agua embotellada, generan conflictos no solamente entre las mismas agencias, sino también con los activistas que se organizan para promover el derecho humano al agua y con las empresas embotelladoras.

Más aún, es preocupante que incluso burócratas mexicanos de la Comisión Nacional del Agua (CONAGUA) indiquen con entusiasmo que la privatización del suministro de agua es deseable e incluso debe ser replicada (Hernández, 2013). Este tipo de actitudes evidencia la completa desconexión que existe entre las funciones que tienen los organismos operadores de agua en la escala local y los valores que 
presentan los funcionarios del organismo rector del agua a nivel nacional.

En conclusión, los datos, argumentos y evidencia empírica presentados en este trabajo demuestran la necesidad de expandir el diálogo sobre privatización del agua para incluir los aspectos políticos de la mercantilización de los recursos hídricos. Como algunas investigaciones empíricas demuestran, los cambios en los patrones de consumo no son individualizados ni tampoco tienen explicaciones monocausales. Van Der Linden demuestra, con su análisis experimental de las respuestas de cuatrocientos cincuenta y cuatro estudiantes holandeses a modificaciones en las condiciones de suministro realizadas para evaluar los cambios en comportamiento por parte de los mismos, que los estudiantes cambian al menos sus intenciones y actitudes de maneras más amigables al ambiente (y con menos intención o interés de adquirir y consumir agua embotellada) cuando se les proporciona información con respecto a los efectos negativos del consumo del líquido envasado con respecto de la sustentabilidad global del suministro de agua (Van Der Linden, 2013). Este tipo de estudios recientes conllevan la necesidad de estudiar el fenómeno del crecimiento en el consumo del agua embotellada con una perspectiva interdisciplinaria y explorando múltiples hipótesis sobre el mismo. En la siguiente sección presento las conclusiones globales del artículo y propongo una alternativa para fortalecer el marco regulatorio mexicano en materia de agua embotellada.

\section{Conclusiones}

El análisis presentado en el artículo demuestra que el negocio de agua embotellada en México no ocurre en un vacío político, sino que confluyen una serie de variables que incluyen conceptualizaciones de la incapacidad de los 
municipios para proveer a los ciudadanos de agua potable para consumo humano con la infraestructura actual, un marco regulatorio e institucional débil que ha promovido simultáneamente la privatización de la provisión del vital líquido y su mercantilización, y finalmente una estrategia ingeniosa de mercadotecnia acoplada con el ejercicio de estrategias exitosas de presión hacia los gobiernos nacionales, forzándolos a darles condiciones sumamente ventajosas para realizar la extracción, embotellamiento y distribución de agua, incluso en zonas de alto estrés hídrico.

Mi análisis demuestra que la fuerza mercadotécnica de las grandes transnacionales del negocio del agua, el cambio en patrones de consumo por parte de los ciudadanos y la transformación de ideas con respecto de la seguridad y salubridad del líquido distribuido por las redes de infraestructura local, la portabilidad de las botellas de agua y la confiabilidad en la calidad del vital líquido, se han entrelazado para dar lugar a un fenómeno de incremento exacerbado de la provisión privada de un recurso natural, el cual ha sido objeto de cambios constitucionales para darle a los ciudadanos el derecho humano a su acceso.

Como he demostrado en las secciones anteriores, la percepción del público en México de la capacidad de los municipios de proveer a los ciudadanos con agua potable para consumo humano de adecuada calidad es realmente pobre. Los municipios, ciertamente, son el orden de gobierno encargado de proveer el servicio de agua potable, alcantarillado y saneamiento en México. Sin embargo, es importante hacer notar que las capacidades instaladas de los municipios son altamente heterogéneas.

La transformación reciente de los marcos regulatorios, tanto en relación con la venta de bebidas gaseosas de sabor (con la inserción e implementación de un impuesto a los 
refrescos), ${ }^{26}$ como la promoción del consumo de agua no embotellada en instalaciones comerciales (con el mandato obligatorio de proveer agua no embotellada gratuita en los restaurantes),${ }^{27}$ ha sido recibida como una estrategia de política pública que envía señales contradictorias, incluso cuando uno pudiera pensar que son tácticas complementarias.

Por un lado, el impuesto contra el refresco parece enviar la señal de que los patrones de consumo de bebidas gaseosas se verán afectados por el incremento en el precio. Pero para garantizar que haya cambio de conducta, también se regula a los restaurantes, quienes generalmente son los que promueven la adquisición de botellas de agua embotellada con el consumo de alimentos. Sin embargo, como he demostrado en páginas anteriores, no se puede fusionar el análisis de las bebidas gaseosas con el estudio del agua embotellada. Si bien en ambos casos el producto analizado es agua, las características físico-químicas y de degustación de ambos son completamente divergentes, se usan en circunstancias distintas y sus patrones de consumo no son idénticos. Una perspectiva integradora no necesariamente tiene que entremezclar ambos productos, ni perspectivas analíticas.

El impuesto al refresco ha tenido una gran variedad de ataques en contra, mayormente de las compañías embotelladoras (Melgar, 2013), que obviamente ven un riesgo sustancial para la operación de sus negocios, pero, por otro lado, instancias gubernamentales tales como la Secretaría de Salud y el Instituto Nacional de Salud Pública han creado campañas sumamente agresivas para promover el establecimiento de un impuesto al refresco. Algunos meses después de esto, el gobierno mexicano también ha arrancado

26. Tema que será abordado en un artículo distinto.

27. Aparentemente esta es una iniciativa de la Secretaría de Salud del Distrito Federal, y no aplica en el resto del territorio mexicano, sino únicamente en la jurisdicción del D. F. Será abordado en un artículo distinto. Para más detalles se recomienda consultar el siguiente enlace: http://www.huffingtonpost.com/huff-wires/20I40I24/ amn-gen-mexico-agua-legislacion/?utm_hp_ref=homepage\&ir=homepage 
una serie de medidas orientadas a disminuir el consumo de agua embotellada en México, pero al igual que el impuesto al refresco, ambas medidas se antojan reaccionarias y poco fundamentadas en un análisis riguroso.

El análisis presentado en este artículo presenta las diferentes variables que permiten explicar la evolución del comportamiento en el consumo de agua embotellada en México y en el mundo. La industria del agua embotellada se está transformando y es importante poder analizarla de manera rigurosa, sólida y sin dejar de lado las peculiaridades que este negocio tiene. Es precisamente este proceso de transición y transformación el que pone de relieve la importancia de discutir el tema del agua embotellada desde la perspectiva de las ciencias sociales, y específicamente, a través de un análisis a través de la óptica de las instituciones, los intereses y las ideas. Uno no puede dejar de analizar el proceso de privatización del agua sin tomar en cuenta los cambios en patrones de consumo, los marcos regulatorios debilitados y las estrategias mercadotécnicas de los grandes conglomerados que envasan el vital líquido para su adquisición y consumo.

Fecha de recepción: 1 de enero de 2014 Fecha de aceptación: 12 de marzo de 2015

Bibliografía

\section{6}

Azpiazu, D. (2004). "Privatización del sistema de agua potable y saneamiento en el Área Metropolitana de Buenos Aires, Argentina”. Revista de Gestión del Agua de América Latina, I ( I), 5- I I.

Bakker, K. (2002). "From state to market?: water mercantilización in Spain”. Environment and Planning A, 34(5), 767-790. 
(2010). Privatizing water: Governance failure and the Bibliografía world's urban water crisis. Ithaca, Nueva York, Estados Unidos: Cornell University Press.

Barringer, F. (I5 de diciembre de 20I I). "Parks chiefs sets conditions for plastic bottle bans". The New York Times. Recuperado de: http://www.nytimes.com/20I I/I2//6/ us/park-service-relents-on-plastic-bottle-ban.html? $r=4 \&$

Black, R. (2009). "Acqua minerale di Sangemini: the Italian mineral water industry finds a place at the table".Journal of Modern Italian Studies, I4(2), I84- 98.

Caldera Ortega, A. R. (2006). "Agua, participación privada y gobernabilidad en Aguascalientes (1989-200I)", en David Barkin (ed.), El Agua Urbana en México: Retos, Debates y Bienestar (pp. 197-216). México: Universidad de Guadalajara.

Carpenter, M. (I 6 de julio de 2007). "Cities looking to ban bottled water". Pittsburgh Post Gazette. Recuperado de: http://news.google.com/newspapers?nid= $1842 \&$ dat $=2$ $00707 \mid 6 \& i d=0$ EweAAAAIBA $\mid \& s j i d=$ MccEAAAAIBAJ \&pg $=3338,2016199$

Castro del Campo, N.y Chaidez Quiroz, C. (20I I)."Bacteriological Quality of Bottled Water in Mexico". Water Conditioning and Purification, (October), I-4.

CBC News (27 de abril de 20I0). "N.S. government ban on bottled water applauded”. Recuperado de: http://www. cbc.ca/news/canada/nova-scotia/n-s-government-banon-bottled-water-applauded-I.89307।

Clarke,T. (I I de diciembre de 2008). "Toronto stood up to bottled water industry”. Recuperado de: http://www. thestar.com/opinion/2008/I2/I I/toronto_stood_up_ to_bottled_water_industry.html

CNN México (29 de septiembre de 20II). "El Senado mexicano eleva a rango constitucional el derecho al agua". Recuperado de: http://mexico.cnn.com/nacio- 
Bibliografía nal/20 I I/09/29/el-senado-mexicano-eleva-a-rangoconstitucional-el-derecho-al-agua

Coca Cola (2015). “Grupos embotelladores”. Recuperado de: http://www.coca-colamexico.com.mx/grupos_ embotelladores.html

Coleman, T. (2012). "Who Owns the Water ?". Intersections, $12(2), 1-19$.

Da Cruz, J. (2006). "Agua embotellada: Signo de nuestro tiempo”. Observatorio de La Globalización, Mayo (5), I-6.

Davis, J. (2005). "Private-Sector Participation in the Water and Sanitation Sector". Annual Review of Environment and Resources, 30(I), I45-I83.

Domínguez Alonso, A.P.(20I I).“La prestación de los servicios de abastecimiento de agua potable y saneamiento por parte de los municipios en México". Multidisciplina, 9(9), 5 - 16.

Durán, J. M.y Torres, A. (2004). “Los costos ambientales del abastecimiento de agua a las ciudades. El caso de la zona metropolitana de Guadalajara. Algunas reflexiones sobre el abastecimiento de agua a la ZMG y el proyecto Arcediano". Carta Económica Regional, I 7(90), 29-40.

El Financiero (10 de junio de 2013). "Agua embotellada, un negocio en crecimiento en México". Recuperado de: http://www.elfinanciero.com.mx/empresas/agua-embotellada-un-negocio-en-crecimiento-en-mexico.html

Enciso, A. (3 de junio de 2009). “Embotelladoras venden el agua 10 mil veces más cara: experto”. La Jornada. Recuperado de: http://www.jornada.unam.mx/2009/06/03/ sociedad/039n I soc

Excelencias Gourmet (I0 de abril de 2009). "México es el segundo país que más agua embotellada consume en el mundo". Recuperado de: http://www.excelenciasgourmet.com/noticia/mexico-es-el-segundo-pais-que-masagua-embotellada-consume-en-el-mundo 
Flaherty, B.; Pacheco-Vega, R. e Isaac-Renton, J. (20I I). "Moving forward in Canada - United States transboundary water management : an analysis of historical and emerging concerns”. Water International, 36(7), 924-936.

Flores, J. (I 4 de noviembre de 2013). "Exigen invertir presupuesto en bebederos para escuelas”. Veo verde. Recuperado de: https://www.veoverde.com/20 I3/ I I/exigeninvertir-presupuesto-en-bebederos-para-escuelas/

Furlong, K. (20I2). “Good water governance without good urban governance? Regulation, service delivery models, and local government". Environment and Planning A, 44(I I), 272I-274I.

Galiani, S.; Gertler, P. y Schargrodsky, E. (2005). “Water for Life :The Impact of the Privatization of Water Services on Child Mortality". Journal of Political Economy, I I3(I), 83- 120.

Gelb, K. (2007). Thirsting for Access? Public Access to Water for Personal Use in Urban Centres:A Case Study ofVictoria, British Columbia.Victoria: University of Victoria.

Hardoy, A. y Schusterman, R. (2000). "New models for the privatization of water and sanitation for the urban poor". Environment and Urbanization, I2(2), 63-76.

Harrison, K. (2002). "Ideas and Environmental StandardSetting:A Comparative Study of Regulation of the Pulp and Paper Industry". Governance, I5(I), 65-96.

Hernández, I. (25 de junio de 20I3). “IP, mejor operador de agua”. Pulso. Diario de San Luis. Recuperado de: http://pulsoslp.com.mx/20 I3/06/25/ip-mejor-operador-de-agua/

Hoberg, G. (2002). "Policy Cycles and Policy Regimes: A Framework for Studying Policy Change”, en B. Cashore, G. Hoberg, M. Howlett, J. Rayner y J.Wilson (eds.), In Search of Sustainability: British Columbia Forest Policy in the 1990s (PP. I-3I).Vancouver: UBC Press. 
Bibliografía

Howlett, M. (2009).“Policy analytical capacity and evidencebased policy-making: Lessons from Canada”. Public Administration, 52(2), I53-I 75.

Gómez, I. (2I de noviembre de 20I3). "Capitalinos exigen bebederos públicos”. Más por más DF. Recuperado de: http://www.maspormas.com/nacion-df/df/capitalinosexigen-bebederos-publicos

Kaplan, M. (2007). "Fijian Water in Fiji and New York: Local Politics and a Global Commodity”. Cultural Anthropology, 22(4), 685-706.

La Jornada de Oriente ( 13 de noviembre de 20 I3).“México, le mejor negocio de embotelladoras de agua como Nestlé y Coca Cola". Recuperado de:http://www.lajornadadeoriente.com.mx/20 I3/ I I/I3/mexico-el-mejor-negociode-embotelladoras-de-agua-como-nestle-y-coca-cola/

Locker, M. (4 de enero de 20I3)."Massachusetts town bans plastic water bottles". Time. Recuperado de: http:// newsfeed.time.com/2013/01/04/massachusett-townbans-plastic-water-bottles/

Machado, D. (28 de julio de 20I3). "México es el tercer país en consumo de agua embotellada superado por Estados Unidos y China". Más por más DF. Recuperado de:http://www.maspormas.com/nacion-df/df/el-mayorconsumidor-de-agua-embotellada-en-mexico

Melgar, I. (18 de octubre de 2013). "Nuevo impuesto a refresco y chatarra". Excelsior. Recuperado de: http:// www.excelsior.com.mx/nacional/20I3/I0/I8/924II5

Montero Contreras, D. (2006)."El agua embotellada en América del Norte: Un negocio jugoso en pocas empresas". Denarius. Revista de Economía y Administración, I2(I), I89-220.

(2008). "La disponibilidad de agua en México y la participación de los grandes conglomerados internacionales". Denarius. Revista de Economía y Administración, 16(2), $103-126$. 
Morales, R. (I4 de junio de 20I2). “Auge de agua embotellada en el país”. El Economista. Recuperado de: http:// eleconomista.com.mx/industrias/20 I 2/06/ /4/auge-aguaembotellada

Noguerón Silva, R. (I ${ }^{\circ}$ de octubre de 20I3). "El agua embotellada. Aún mejor negocio que los refrescos”. Revista digital Enlace México. Recuperado de: http://www.enlacemexico.info/index. php?option=com_content\&view $=$ article\&id $=5940$ :elagua-embotellada-aun-mejor-negocio-que-losrefrescos\&catid $=69:$ monkey-business\&ltemid $=110$

Pacheco-Vega, R. (20I2)."Arreglos institucionales dentro de la cuenca Lerma-Chapala: Una visión desde la política ambiental", en M. Sánchez Rodríguez, J. de J. Hernández López, J. M. Durán Juárez y A. Torres Rodríguez (eds.), Los estudios del agua en la cuenca Lerma-Chapala-Santiago. Agricultura, industria y ciudad. Pasado y presente (pp. 347360). Zamora: El Colegio de Michoacán.

(2013). "Polycentric water governance in Mexico: Beyond the governing-by-river-basin-council model", en LASA (eds.), 2013 Meeting of the Latin American Studies Association (LASA) (PP. I-30). Washington, D.C.: Latin American Studies Association.

yVega, O. (2008). "Los debates sobre la gobernanza del agua:Hacia una agenda de investigación en México", en D. Soares, S. Vargas-Velázquez y R. Nuño (eds.), La Gestión de Recursos Hidráulicos: Realidades y Perspectivas (Tomo I) (pp.57-86). Guadalajara: Instituto Mexicano de Tecnología del Agua/Universidad de Guadalajara.

Pirez, P. (2002). "Buenos Aires: fragmentation and privatization of the metropolitan city". Environment and Urbanization, I 4(I), I 45-I 58.

Pritchard, D.; Douglas, A. y Zhang, Jimson (20I0). An Investigation into Sustainable Water Consumption in the University of British Columbia's New Student Union Building Project. 
Bibliografía
Vancouver: University of British Columbia. Recuperado de: http://sustain.ubc.ca/sites/sustain.ubc.ca/files/ seedslibrary/APSC26I_SustainableWaterConsumption_Group05_Clean.pdf

Race, K. (20I2). "Frequent Sipping”: Bottled Water, the Will to Health and the Subject of Hydration". Body \& Society, I8(3/4), 72-98.

Saarikoski, H.; Raitio, K. y Barry, J. (20I3). “Understanding "successful" conflict resolution: Policy regime changes and new interactive arenas in the Great Bear Rainforest". Land Use Policy, 32, 27I-280.

Salzman, J. (20I2). Drinking Water:A History. Nueva York:The Overlook Press.

Schmidt, J.J.y Mitchell, K. R. (2013)."Property and the Right to Water:Toward a Non-Liberal Commons". Review of Radical Political Economics, 46(I), 54-69.

Shiva, V. (2002). Water wars. Privatization, pollution, and profit. Cambridge, Massachusetts, Estados Unidos: South End Press.

Smith, K. (30 de abril de 2007). "Charlottetown mayor orders halt to bottled water". The Guardian. Recuperado de:http://www.theguardian.pe.ca/Regional/2007-04-30/ article-I372945/Charlottetown-mayor-orders-halt-tobottled-water/I

The Independent ( 10 de junio de 20 I I). "Canadian province bans bottled water”. Recuperado de: http://www.independent.co.uk/environment/canadian-province-bansbottled-water-22956 I4.html

Trottier, C.; Ferguson, P.; Cook, V.; Maggio, Z. y Cressy, J. (2009). Murky Waters: The Urgent Need for Health and Environmental Regulations of the Bottled Water Industry. Ottawa, Canadá: Polaris Institute.

Ulrich, J. D. (2009). "It is a strange thing for us to see water being sold": Local perceptions of the Fijian bottled water industry. Tesis para obtener el grado de Master of Arts 
in Sociology, Inequality and Social Justice. The University

Bibliografía of Montana.

Van Der Linden, S. (20/3). “Exploring beliefs about bottled water and intentions to reduce consumption: The dual-effect of social norm activation and persuasive information". Environment and Behavior, XX(X), I-25, doi: I0.1I77/0013916513515239

Welsh, Nick. (28 de junio de 2007). "Bottled water ban”. Santa Barbara Independent. Recuperado de: http://www. independent.com/news/2007/jun/28/bottled-water-ban/

Páginas de internet www.ordenjuridico.gob.mx. Consultada el 17 de marzo de 2015 